\title{
Preface to the Industrial Track
}

The aim of the ER'11 Industrial Track was to serve as a forum for high quality presentations on innovative commercial software, systems, and services for all facets of conceptual modeling methodologies and technologies as described in the list of topics of the ER 2011 conference. We strongly believe that bringing together researchers and practitioners is important for the progress and success of research on conceptual modeling. We do hope that this track will become stronger year by year and will serve as an excellent opportunity to discuss current practices and modern and future market trends and needs.

The 2011 edition formed two interesting sessions on advanced and novel conceptual model applications.

The first session included three papers on business intelligence applications. The first two papers present tools than assist the data warehouse designer. QBX is a case tool that facilitates data mart design and deployment. TARGIT BI Suite assists the designer to add associations between measures and dimensions to a traditional multidimensional cube model and facilitates a process where users are able to ask questions to a business intelligence system without the constraints of a traditional system. The third paper presents a tool that implements an entity resolution method for topic-centered expert identification based on bottom-up mining of online sources.

The second session included three papers on emerging industrial applications of conceptual modeling. The first paper presents a model-driven solution toward the provision of secure messaging capabilities to the financial services industry through the standardization of message flows between industry players. The second paper presents the underlying scientific theories, methodology, and software technology to meet the requirements of high quality technical documentation. The third paper presents a real case of using business semantics management for integrating and publishing research information on an innovation information portal.

We hope that you will enjoy the industrial track proceedings and find useful information and motives to extend your research to new horizons. We would like to express our gratitude to all authors who submitted papers and talk proposals, the members of the program committee for their help and efforts in organizing this track, and the ER 2011 organizing committee and ER steering committee for all their support.

July 2011

Alkis Simitsis

Hans Van Mingroot

O. De Troyer et al. (Eds.): ER 2011 Workshops, LNCS 6999, p. 357, 2011.

(c) Springer-Verlag Berlin Heidelberg 2011 